\title{
Controlled Grain Refinement of Biodegradable Zn-Mg Alloy: The Effect of Magnesium Alloying and Multi-Pass Hydrostatic Extrusion Preceded by Hot Extrusion
}

\author{
ANNA JARZEBSKA, MAGDALENA BIEDA, LUKASZ MAJ, ROBERT CHULIST, \\ DANIEL WOJTAS, MARTYNA STRĄG, BARTOSZ SUŁKOWSKI, \\ SYLWIA PRZYBYSZ, WACŁAW PACHLA, and KRZYSZTOF SZTWIERTNIA
}

\begin{abstract}
To satisfy the most stringent criteria in terms of new cardiovascular stents, pure $\mathrm{Zn}$ was alloyed with $1 \mathrm{wt}$ pct of $\mathrm{Mg}$ and subsequently subjected to plastic deformation, using conventional hot extrusion followed by multi-pass hydrostatic extrusion. A detailed microstructural and textural characterization of the obtained materials was conducted, and mechanical properties were assessed at each pass of deformation process. In contrast to pure Zn, hydrostatically extruded low-alloyed $\mathrm{Zn}$ is characterized by a remarkable increase in strength and ductility (YS $=383 \mathrm{MPa}, E=23 \mathrm{pct}$ ), exceeding the values needed for stents. Such behavior is associated with a dual microstructure containing fine-grained $\mathrm{Zn}$, alternatively arranged with bands of a fragmented eutectic. Extensive grain refinement was achieved due to the process of continuous dynamic recrystallization. Hydrostatic extrusion changes the initial $\langle 10 \overline{1} 0\rangle$ fiber texture to a $\langle 0002\rangle$ and $\langle 10 \overline{1} 1\rangle$ double fiber texture in which the $\langle 0002\rangle$ component decreases with each pass of hydrostatic extrusion. The gradual evolution of texture components was simulated using a visco-plastic self-consistent model, which confirmed that, during hydrostatic extrusion, secondary slip systems were activated involving mostly the pyramidal one.
\end{abstract}

https://doi.org/10.1007/s11661-020-06032-4

(C) The Author(s) 2020

\section{INTRODUCTION}

BIODEGRADABLE metals are a new generation of materials which may be used in medical devices to improve patients' lives significantly. They can be used for producing temporary implants, which will dissolve in a human body after completing their mission of supporting the healing process of damaged tissue. ${ }^{[1]}$

ANNA JARZEBSKA, MAGDALENA BIEDA, ŁUKASZ MAJ, ROBERT CHULIST, MARTYNA STRĄG, and KRZYSZTOF SZTWIERTNIA are with the Institute of Metallurgy and Materials Science, Polish Academy of Sciences, 25 Reymonta St., 30-059, Krakow, Poland. Contact e-mail: a.jarzebska@imim.pl DANIEL WOJTAS is with the Institute of Metallurgy and Materials Science, Polish Academy of Sciences and also with the Faculty of Physics and Applied Computer Science, AGH University of Science and Technology, 30-059 Krakow, Poland. BARTOSZ SUŁKOWSKI is with the Faculty of Non-ferrous Metals, AGH University of Science and Technology, 30-059 Krakow, Poland. SYLWIA PRZYBYSZ and WACé AW PACHLA are with the Institute of High Pressure Physics, Polish Academy of Sciences, 01-142 Warsaw, Poland. WACŁAW PACHLA is with the Institute of High Pressure Physics, Polish Academy of Sciences.

Manuscript submitted May 22, 2020; accepted September 15, 2020.

Article published online October 7, 2020
Their degradation should proceed gradually with a harmless response from the host in regard to corrosive products. An example of an implant that does not require a long-term presence in a patient's body is a stent. This small meshed tube used, among other things, in cardiovascular interventions supports artery walls and keeps the lumen open. ${ }^{[2]}$ Specialized application needs a number of properties such as biocompatibility, a steady corrosion rate, and the appropriate combination of mechanical strength and plasticity. ${ }^{[3]}$ Pure $\mathrm{Zn}$ fulfils most of the aforementioned requirements, which makes it a very promising material for biodegradable stents. ${ }^{[4-6]}$ However, as-cast pure $\mathrm{Zn}$ has poor mechanical properties (i.e., yield strength, ultimate tensile strength, elongation to failure). Thus, it is of great importance to improve the strength and plasticity of pure $\mathrm{Zn}$.

Alloying is the most frequently applied method for strengthening biodegradable zinc, especially with elements such as magnesium, calcium or manganese. ${ }^{[7-9]}$ Very promising results were obtained for hypoeutectic $\mathrm{Zn}$ alloyed with $\mathrm{Mg}$, where even a small addition of $\mathrm{Mg}$ yielded a significant increase in the mechanical strength of the as-cast material. ${ }^{[10]}$ Moreover, the addition of $\mathrm{Mg}$ is justified by its excellent biocompatibility. However, 
alloying alone does not meet high criteria for application in biodegradable implants. ${ }^{[11]}$ Therefore, it is often supported by methods of conventional plastic deformation, in particular hot rolling or hot extrusion. ${ }^{[12,13]} \mathrm{A}$ combination of these two methods yielded further improvement in strength, but failed to deliver simultaneous enhancement of all mechanical properties above a rigorous limit. Another solution lies in the use of unconventional methods of plastic deformation.

The number of papers concerning the use of severe plastic deformation (SPD) techniques with $\mathrm{Zn}$ and its alloys is rising. Lately, equal channel angular pressing (ECAP), high pressure torsion (HPT), the KoBo method and hydrostatic extrusion have been proposed..$^{[14-17]}$ Hydrostatic extrusion is a technique allowing intensive plastic deformation, but is an unconventional SPD technique as the reduction in the cross-section of a material during the process occurs. ${ }^{[18]}$ One of the advantages of the method is a complex stress state due to hydrostatic pressure, which enables even hard-to-deform materials to be processed and crack formation to be suppressed effectively. ${ }^{[19]}$ Moreover, high deformation rates promote the accumulation of structural defects and, in consequence, grain refinement, which is of great importance in the case of $\mathrm{Zn}$ and its alloys characterized by relatively low recrystallization temperature. Grain refinement is determined by true strain, which is related to the reduction in a cross-section of a deformed material, which can be ensured in a single or multi-pass way. Our first results showed that hydrostatic extrusion, especially combined with magnesium alloying, can be suitable for obtaining materials that meet high requirements for biodegradable stents. ${ }^{[20]}$ As shown in Reference 21, adding different magnesium content and increasing the number of passes leads to grain refinement and strengthens $\mathrm{Zn}-\mathrm{Mg}$ alloys.

However, to determine the optimum values for mechanical properties, further microstructure and texture investigations of hydrostatically extruded low-alloyed zinc are necessary. Detailed microstructural characterization is of great significance in order to provide a better understanding of strengthening mechanisms and to control the mechanical properties of newly developed materials.

The novelty proposed in this work consists of hot extrusion followed by multi-pass hydrostatic extrusion, and resulted in patent applications. ${ }^{[22]}$ In this study, comprehensive analysis of microstructure and texture evolution during the multi-pass hydrostatic extrusion of low-alloyed $\mathrm{Zn}$ was carried out and related to mechanical properties. The obtained results were compared to metals processed by hot extrusion, as that is the most commonly utilized method of improving the mechanical properties of low-alloyed $\mathrm{Zn}$ and to pure Zn processed by hydrostatic extrusion. That overview allows emphasis on the effect of multi-pass hydrostatic extrusion combined with prior hot extrusion and magnesium addition, in order to demonstrate the benefits of the proposed method for obtaining a material with high mechanical properties suitable for biodegradable stent application.

\section{MATERIALS AND METHODS}

The materials used in the present study were pure $\mathrm{Zn}$ and $\mathrm{Zn}$ with addition of $1 \mathrm{wt}$ pet of $\mathrm{Mg}$ ( $\mathrm{Zn}-1 \mathrm{Mg}$ alloy). They were prepared by gravity casting using steel molds of melted $\mathrm{Zn}$ or $\mathrm{Zn}$ and $\mathrm{Mg}$ (both 99.99 pet purity) in a Naberthem N20/14 resistance furnace at $650{ }^{\circ} \mathrm{C}$ under an argon atmosphere. In the next step, the as-cast ingots with a diameter of $75 \mathrm{~mm}$ were air-cooled.

A novel method of deformation was applied to the as-cast ingots. First, they were hot extruded (at $250{ }^{\circ} \mathrm{C}$ ) to rods of $30 \mathrm{~mm}$ in a diameter (extrusion ratio $R=5.8$ ). Subsequently, the materials were subjected to a main plastic deformation in the form of multi-pass hydrostatic extrusion performed in four consecutive steps at room temperature with a cumulative true strain $(\varepsilon)^{[23]}$ equal to 3.6 and the final diameter of the extruded rods being $5 \mathrm{~mm}$. The materials were extruded with pressures in the range of 225 to 295 and 430 to $505 \mathrm{MPa}$ for pure $\mathrm{Zn}$ and the $\mathrm{Zn}-1 \mathrm{Mg}$ alloy, respectively. The reduction in a cross-section on each pass of hydrostatic extrusion is listed in Table I.

The hot extruded materials are considered as initial in this paper, with the final material being produced by the hydrostatic extrusion process. The microstructural characterization of the materials was carried out on the longitudinal (LCS) and transverse (TCS) cross-sections to the extrusion direction (ED). It was done mainly based on Electron Backscattered Diffraction (EBSD) maps acquired on an FEI Quanta 3D FEG scanning electron microscope operated at $20 \mathrm{kV}$ and equipped with an EDAX OIM TSL EBSD collecting system. Samples for EBSD investigations were mechanically ground, polished and finally electropolished using $\mathrm{C} 1$ Struers electrolyte at $25 \mathrm{~V}$ for 15 seconds. Data sets obtained from the EBSD measurements in the form of orientation maps were analyzed with TSL OIM Analysis 7 software, based on the assumption that a grain is an area consisting of at least five pixels with the same orientation separated from the other grains by a grain boundary with a misorientation angle higher than $15 \mathrm{deg}$. To obtain high-quality statistics, EBSD data were acquired with a different step and map size, depending on the investigated material. For materials after hot extrusion, a step of $1 \mu \mathrm{m}$ and a size of $1280 \times 1280 \mu \mathrm{m}$ on the LCS and $0.4 \mu \mathrm{m}$ and a size of $512 \mu \mathrm{m} \times 512 \mu \mathrm{m}$ on the TSC was selected. For materials after the first pass of hydrostatic extrusion, a step of $0.2 \mu \mathrm{m}$ and $256 \mu \mathrm{m} \times 256 \mu \mathrm{m}$ was used, and for the rest, $0.1 \mu \mathrm{m}$ and $128 \mu \mathrm{m} \times 128 \mu \mathrm{m}$, regardless of the cross-section tested. Statistical analysis was executed only for grains indexed as belonging to a primary $\alpha-\mathrm{Zn}$ phase. Pixels with a low value of image quality (corresponding to the second phase) were excluded from the calculations based on the individual range of the image quality parameter of a particular map. The average grain size was determined on the basis of the weighted average grain diameter, where the weight is area of the grain (area fraction approach). Additionally, standard deviation was reported for this value. The area fraction of low and high angle grain boundaries specified as a boundary with misorientation angle from range $\Theta=2$ 
Table I. The Cumulative True Strain and Reductions in Cross-Section on Each Pass of Hydrostatic Extrusion

\begin{tabular}{lccccc}
\hline & Hot Extrusion & 1st Pass & 2nd Pass & 3rd Pass & 4th Pass \\
\hline Cumulative True Strain $(\varepsilon)$ & 0 & 1 & 2 & 2.8 & 3.6 \\
Reduction (Diameter) $[\mathrm{mm}]$ & 30 & 17.8 & 10.9 & 5.5 \\
\hline
\end{tabular}

to $15 \mathrm{deg}$ (low-angle grain boundary-LAGB) and $\Theta>15 \mathrm{deg}$ (high angle grain boundary-HAGB), respectively, was measured as a length of individual boundary divided by the area of the collected orientation map. Pole figures were calculated from EBSD data. The texture analysis of the initial material was performed using high-energy synchrotron $\mathrm{X}$ - ray radiation at DESY Hamburg Germany, using a beam line P07B $(87.1 \mathrm{keV}, \lambda=0.0142342 \mathrm{~nm}){ }^{[24]}$

Transmission electron microscopy (TEM) observations were also carried out in bright-field (TEM/BF) mode together with the acquisition of selected area electron diffraction (SAED) patterns with the use of an FEI Tecnai G2 $200 \mathrm{kV}$ FEG microscope. Indexing of SAED patterns was done using CSpot software. ${ }^{[25]}$ The samples for TEM investigations were electropolished at $30 \mathrm{~V}$, employing a TenuPol-5 electropolishing machine and using an electrolyte consisting of perchloric acid (5 pct) and ethanol, cooled down to $-30{ }^{\circ} \mathrm{C}$.

The uniaxial static tensile tests were carried out on a Zwick/Roell Z250 kN machine, at a constant strain rate of $8 \times 10^{-3} \mathrm{~s}^{-1}$ on cylindrical samples (three samples for each material condition) with a length to diameter ratio of $5: 1$.

In this study, a visco-plastic ${ }^{[26,27]}$ model was used to investigate the evolution of texture during the deformation of $\mathrm{Zn}-1 \mathrm{Mg}$ alloy. Slip systems such as three basal $(0001)\langle 11 \overline{2} 0\rangle$, three prismatic $\{10 \overline{1} 0\}\langle 1 \overline{2} 10\rangle$ and six pyramidal second order $\{11 \overline{2} 2\}\langle 11 \overline{2} 3\rangle\left(\pi^{2}\right)$ slip systems were investigated. The critical resolved shear stress for the investigated slip systems were $\tau_{\mathrm{B}}=1.5 \mathrm{MPa}$, $\tau_{\mathrm{P}}=5 \mathrm{MPa}$ and $\tau_{\pi 2}=20 \mathrm{MPa}$, respectively. However, during the simulations, the magnitude of critical resolved shear stress was varied to change the contribution of particular slip systems. The strain rate sensitivity parameter was equal for all slip systems, amounting to $m=0.03$, and the referential shear strain was $\dot{\gamma}_{0}=0.01$.

\section{RESULTS}

$\mathrm{SEM} / \mathrm{BSE}$ observations revealed the differences in microstructure of materials after hot extrusion. As can be seen in Figures 1(a) and (b), pure Zn was characterized by large equiaxed grains. Microstructure investigations performed on the both perpendicular cross-sections showed the bimodal character of pure $\mathrm{Zn}$ grains. The grain size distribution varies over a wide range between 25 and $430 \mu \mathrm{m}$. The neighboring grains, irrespectively of size, were mostly separated by HAGBs. The addition of $\mathrm{Mg}$ caused the formation of a eutectic mixture composed of $\alpha-\mathrm{Zn}$ and $\mathrm{Mg}_{2} \mathrm{Zn}_{11}$ intermetallic phase. ${ }^{[12]}$ The eutectic was located at the boundaries of primary $\alpha-\mathrm{Zn}$ grains, as can be seen in Figures 1(c) through (f). The EBSD measurements presented in Figure 1 show that the addition of $\mathrm{Mg}$ contributed significantly to grain refinement. A large decrease in the average grain size (AGS), from 272.2 to $33.8 \mu \mathrm{m}$ for the $\mathrm{Zn}-1 \mathrm{Mg}$ alloy was noted (calculated on LCS). In addition, a more homogeneous microstructure composed of slightly elongated grains in the ED within a narrower size range was observed. Based on the distribution of misorientation angle it could be stated that $\mathrm{Mg}$ content caused an increase in the number fraction of LAGBs. Some peaks around $\Theta=86 \mathrm{deg}$ were identified, which can be associated with the presence of twins in the microstructure. ${ }^{[28]}$ Although the spatial resolution of EBSD method is insufficient to provide reliable information about the grain size and texture of the eutectic, the IPF mode combined with image quality factor show its morphology and distribution relatively well, underlining the grain and interphase boundaries. Based on the studies conducted on LCS, it was observed that the eutectic was elongated in the ED, forming a band-like microstructure. A chemical composition map, acquired along with the EBSD measurements, showed that $\mathrm{Zn}$ (shown red in Figures 1(e) and (f)) was evenly distributed throughout the matrix grains, while the eutectic areas become depleted of $\mathrm{Zn}$. This strongly suggests that $\mathrm{Mg}$ accumulated mainly in the intermetallic phase in the eutectic area.

Microstructure analysis of pure $\mathrm{Zn}$ subjected to the multi-pass hydrostatic extrusion showed that such processing caused remarkable grain refinement even after the first pass, as presented in Figure 2. However, at the beginning of the plastic deformation process, the microstructure was bimodal in character. Most of the larger grains, especially on the TCS, showed crystal orientation with the $\langle 0001\rangle$ direction being parallel to the ED. It may be noticed that an increase in true strain affected the orientation of grains in such a way that grains with the $\langle 0001\rangle$ direction parallel to the ED disappear progressively. The following hydrostatic extrusion passes did not cause any further significant grain refinement, although the number of larger grains decreased and the microstructure of pure $\mathrm{Zn}$ became more homogeneous. Microstructure characterization of the $\mathrm{Zn}-1 \mathrm{Mg}$ alloy after hydrostatic extrusion revealed that an addition of $1 \mathrm{wt}$ pet of $\mathrm{Mg}$ to $\mathrm{Zn}$ resulted in further grain refinement as compared with pure $\mathrm{Zn}$ (Figure 3). After the first pass of hydrostatic extrusion, the bimodal character of the microstructure was even more visible than for pure $\mathrm{Zn}$. Another similarity between pure $\mathrm{Zn}$ and $\mathrm{Zn}-1 \mathrm{Mg}$ alloy was the large number of 

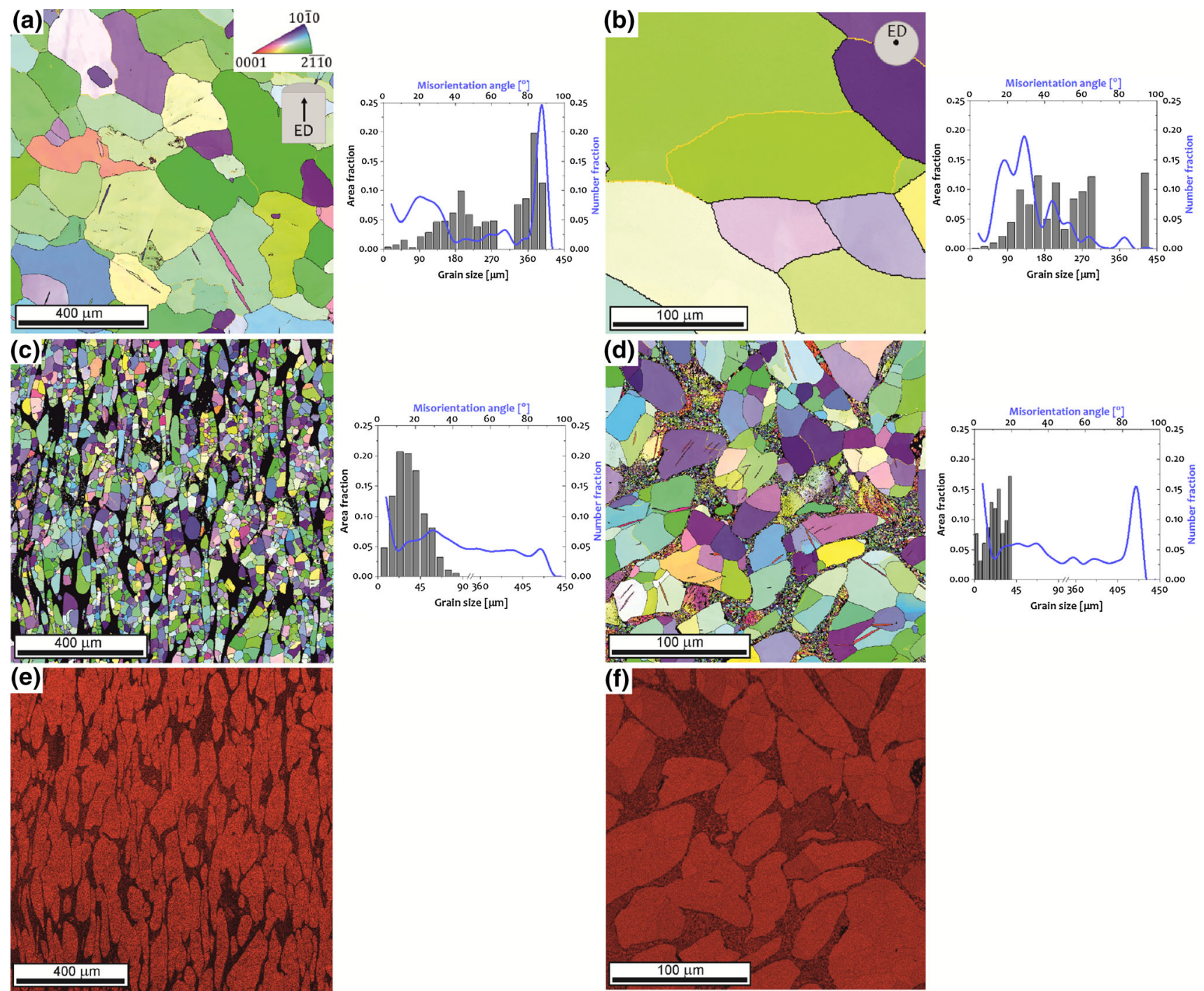

Fig. 1- Orientation maps with corresponding grain size and misorientation angle distributions: left side LCS and right side TCS obtained after hot extrusion of pure $\mathrm{Zn}(a),(b)$ and the $\mathrm{Zn}-1 \mathrm{Mg}$ alloy $(c),(d)$ and chemical composition map indicating $\mathrm{Zn}$ concentration marked red for the $\mathrm{Zn}-1 \mathrm{Mg}$ alloy acquired from the $(e)$ LCS and $(f)$ TSC. The black and yellow lines on the orientation maps correspond to HAGB and LAGB, respectively. The dark area on the orientation map of the $\mathrm{Zn}-1 \mathrm{Mg}$ alloy corresponds to the $\mathrm{Mg}_{2} \mathrm{Zn}_{11}$ intermetallic phase, excluded from the calculations. The inverse pole figure (IPF) colour-coding is shown with respect to the ED using the standard triangle and colours as given at the top of the figure (Color figure online).

grains with the $\langle 0001\rangle$ direction parallel to the ED. In the LCS orientation maps, elongated grains in the ED were still observed even with a higher number of large grains with the $\langle 0001\rangle$ direction parallel to the ED in comparison to pure $\mathrm{Zn}$. Subsequent passes of hydrostatic extrusion decreased the grain size and led to the formation of more homogeneous microstructure. The AGS, depending on the cross-section, differed substantially due to the preserved elongated shape of the grains observed on the LCS. After the last pass of hydrostatic extrusion, equiaxed grains were present on both of the cross-sections, with unchanged AGS. The average values of grain size are summarized and listed in Table II. Hydrostatic extrusion also caused changes in the morphology of the eutectic, and well-developed bands elongated in the ED were formed. As deformation proceeded, those bands became thinned down to a few microns. The arrangement of the fragmented eutectic in the form of well-defined bands was proven through TEM/BF observations of the $\mathrm{Zn}-1 \mathrm{Mg}$ alloy after the fourth pass of hydrostatic extrusion (Figure 4(a)). The SAED patterns confirm the presence of $\alpha-\mathrm{Zn}$ and $\mathrm{Mg}_{2} \mathrm{Zn}_{11}$ phases in the bands (Figure 4(b)).

Analysis of grain boundaries density (GBD) for pure $\mathrm{Zn}$ after hydrostatic extrusion revealed that HAGBs constituted more than 90 pet of all grain boundaries, and that their share increased slightly with the number of hydrostatic extrusion passes (Figure 5). In turn, for the hydrostatically extruded alloy $\mathrm{Zn}-1 \mathrm{Mg}$, the generation of a large number of LAGBs was noticed. The highest number of these was obtained after the first pass, decreasing gradually with subsequent passes. 

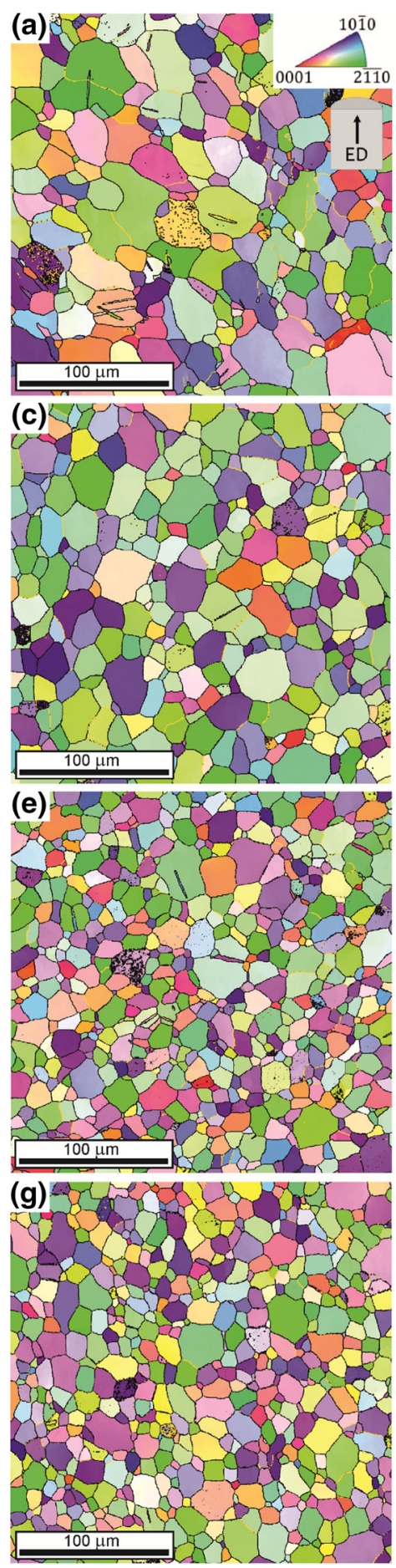
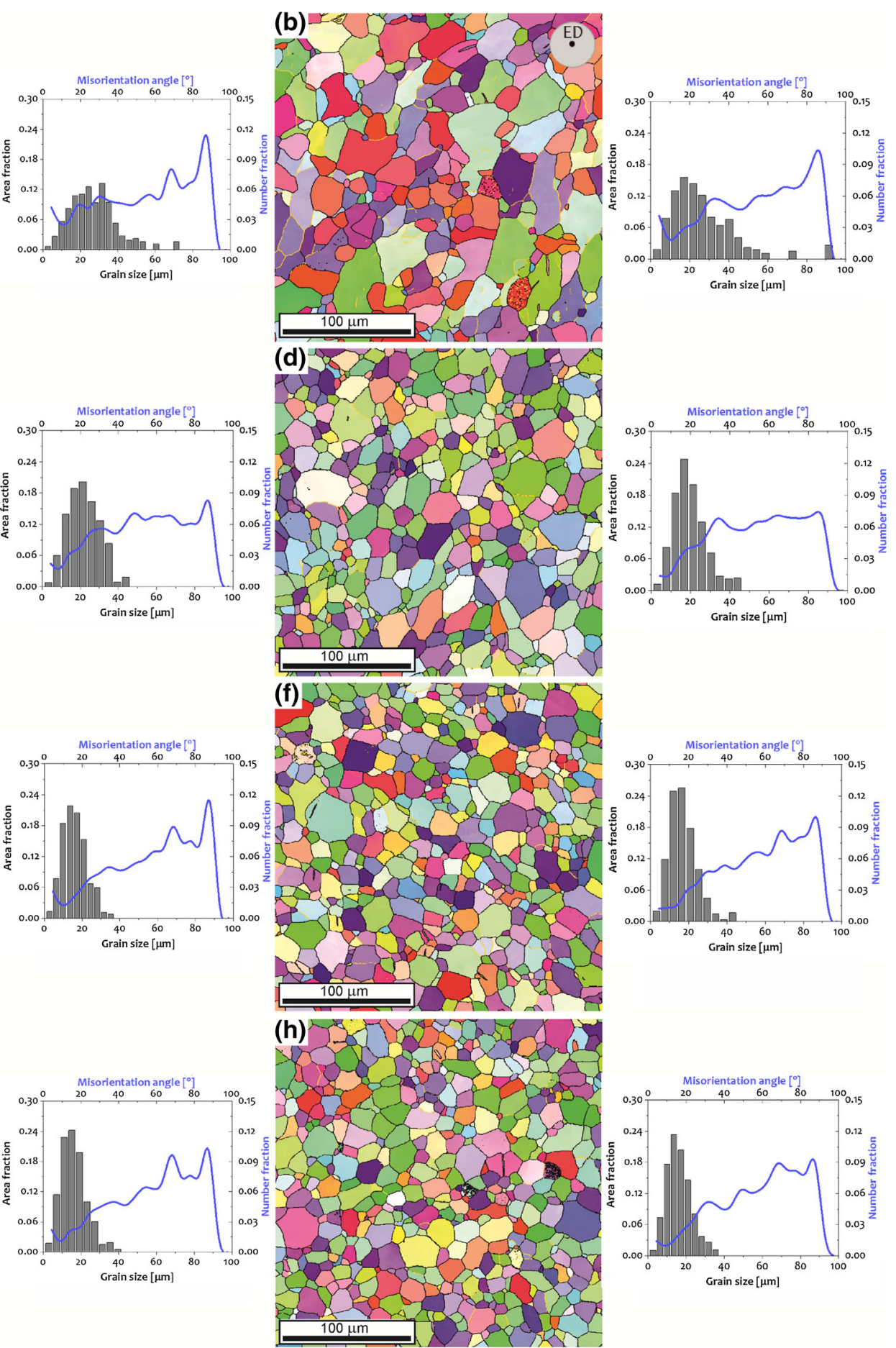

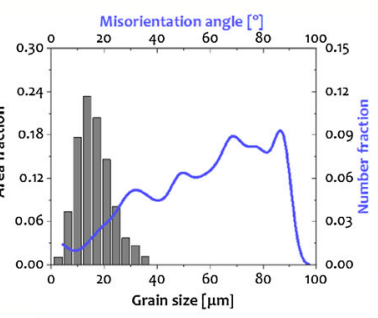

Fig. 2 - Orientation maps with corresponding grain size combined with misorientation angle distributions for pure Zn: left side LCS and right side TCS obtained after hot extrusion followed by hydrostatic extrusion after $(a, b)$ the first pass, $(c, d)$ the second pass $(e, f)$ the third pass and $(g, h)$ the fourth pass. The black and yellow lines on the orientation maps correspond to HAGB and LAGB, respectively. The inverse pole figure (IPF) colour-coding is shown with respect to the ED, using the standard triangle and colours as given at the top of the figure (Color figure online).

The evolution of crystallographic texture after subsequent passes of hydrostatic extrusion was presented based on a series of (0002) and (1011) pole figures (calculated from the EBSD and for materials after hot extrusion employing synchrotron data) (Figure 6) and was qualitatively similar for pure $\mathrm{Zn}$ and $\mathrm{Zn}-1 \mathrm{Mg}$ alloy.
Due to better grain statistics, only the $\mathrm{Zn}-1 \mathrm{Mg}$ was analyzed. The initial fiber $\langle 10 \overline{1} 0\rangle$ texture in which the $\langle 0001\rangle$ direction is perpendicular to ED is typical for hot extruded metals with hexagonal closed packed (HCP) unit cells. ${ }^{[29]}$ Hydrostatic extrusion changes the initial texture to a $\langle 0002\rangle$ and $\langle 10 \overline{1} 1\rangle$ double fiber texture, with 

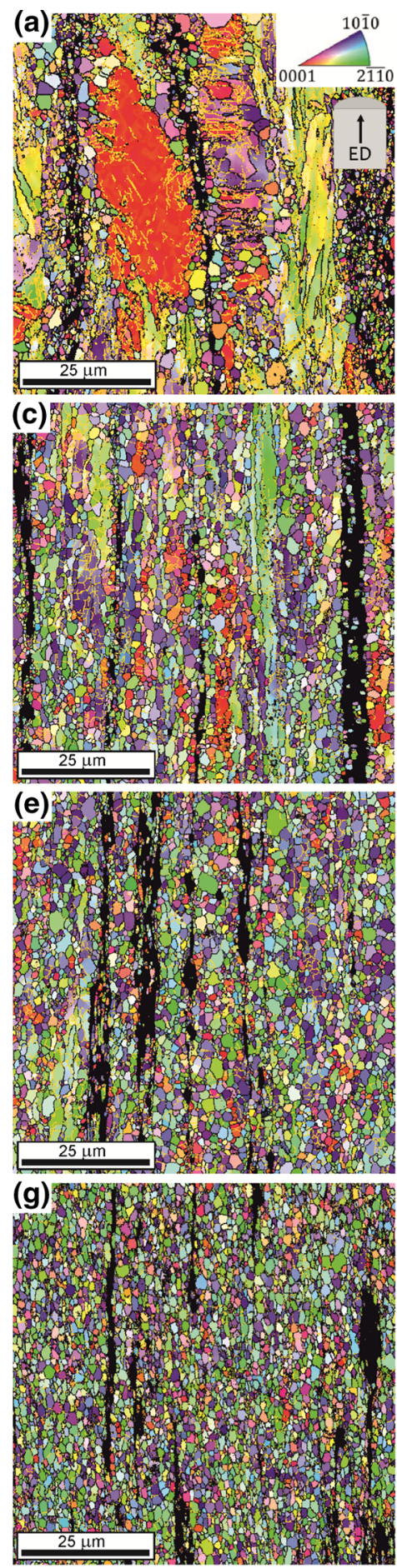
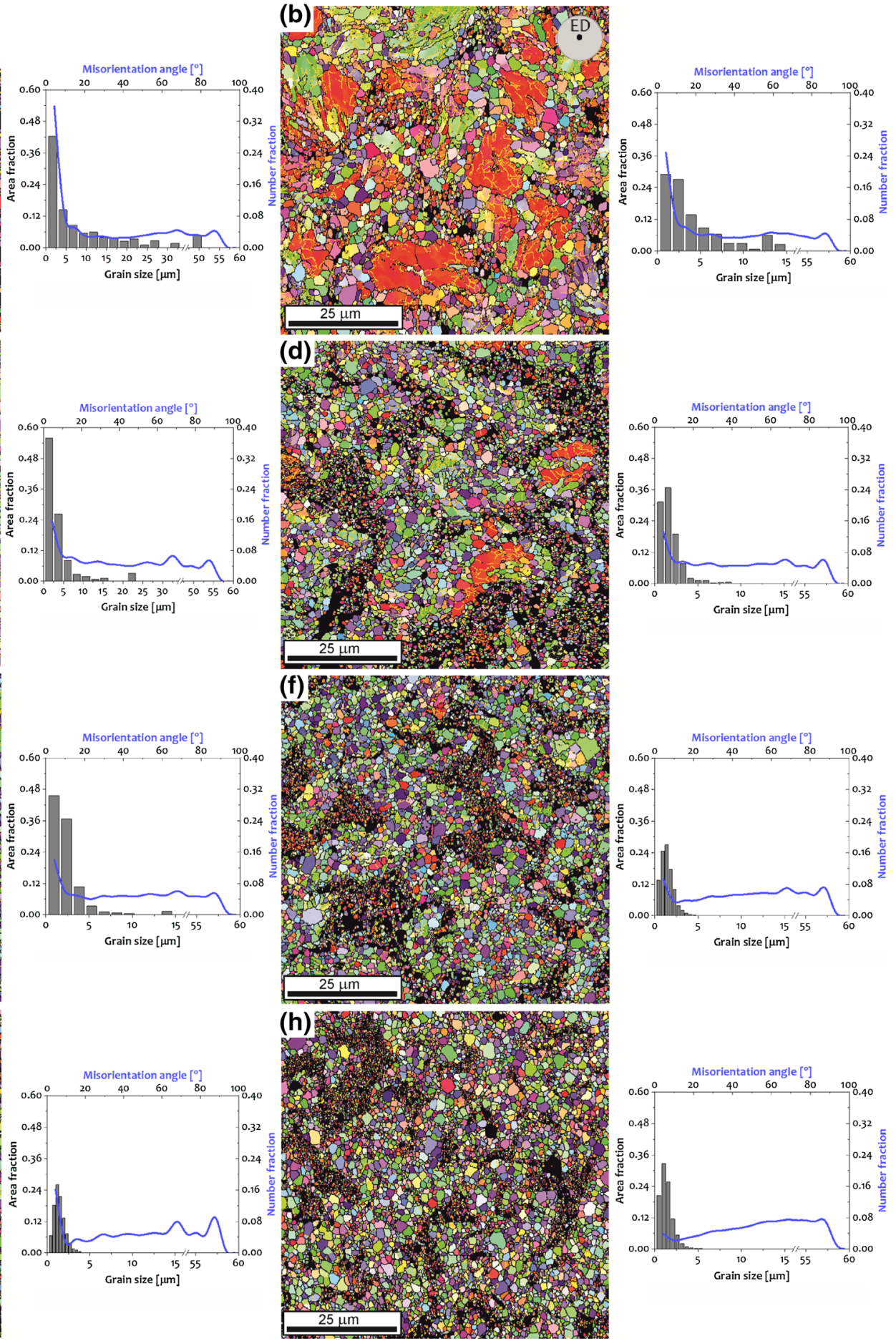

Fig. 3- Orientation maps with corresponding grain size combined with misorientation angle distributions for the $\mathrm{Zn}-1 \mathrm{Mg}$ alloy: left side LCS and right side TCS obtained after hot extrusion followed by hydrostatic extrusion after $(a, b)$ the first pass, $(c, d)$ the second pass $(e, f)$ the third pass and $(g, h)$ the fourth pass. The dark areas on orientation map of the $\mathrm{Zn}-1 \mathrm{Mg}$ alloy correspond to the intermetallic phase of $\mathrm{Mg}_{2} \mathrm{Zn}_{11}$ and were excluded from calculations. The black and yellow lines on the orientation maps correspond to HAGB and LAGB, respectively. The inverse pole figure (IPF) colour-coding is shown with respect to the ED using the standard triangle and colours as given at the top of the figure (Color figure online).

the (0002) being the dominating component after the first pass. Such changes are attributed to compression twinning $\{10 \overline{1} 2\},{ }^{[30]}$ which is presented schematically in Figure 6. As the number of hydrostatic extrusion passes increases, the $\langle 10 \overline{1} 1\rangle$ component grows at the cost of the $\langle 0002\rangle$ component. As can be seen in Figure 7, the volume fraction of $\langle 0002\rangle$ fiber falls to practically zero (about $1.8 \mathrm{pct}$ ) after four passes of hydrostatic extrusion. In this place, the $\langle 10 \overline{1} 1\rangle$ fiber component appears in an amount equal to 33 pct. 
Table II. The Average Grain Size Obtained for All Investigated Materials

\begin{tabular}{lcccr}
\hline Sample & Hot Extrusion & 1st Pass & 2nd Pass & 3rd Pass \\
\hline Zn & & & & 4th Pass \\
LCS $[\mu \mathrm{m}]$ & $272.2 \pm 110$ & $27.1 \pm 13$ & $21.8 \pm 8$ & $16 \pm 6$ \\
TCS $[\mu \mathrm{m}]$ & $226.4 \pm 103$ & $27.3 \pm 17$ & $19.6 \pm 8$ & $17 \pm 7$ \\
Zn-1Mg & & & $3.6 \pm 4$ & $2.3 \pm 2$ \\
LCS $[\mu \mathrm{m}]$ & $33.8 \pm 15$ & $9.6 \pm 12$ & $1.8 \pm 1$ & $1.4 \pm 1$ \\
TCS $[\mu \mathrm{m}]$ & $23.5 \pm 11$ & $4.2 \pm 4$ & & $1.5 \pm 1$ \\
\hline
\end{tabular}
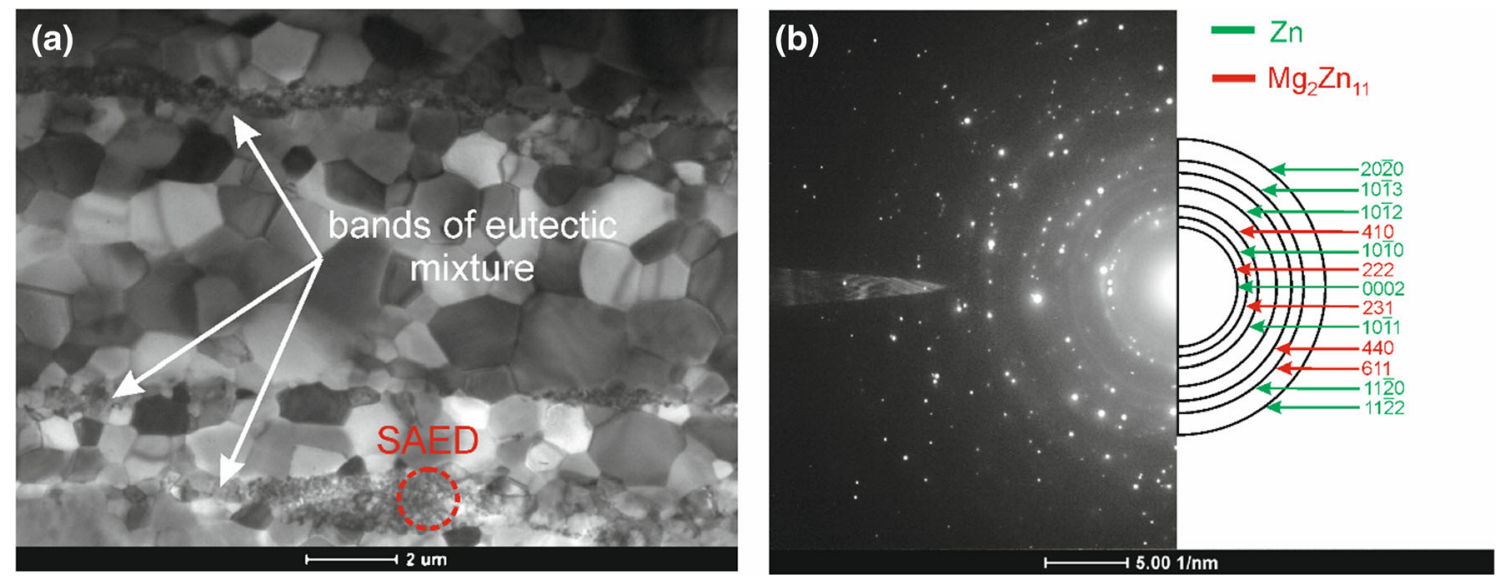

Fig. 4-TEM/BF microstructure image obtained for the $\mathrm{Zn}-1 \mathrm{Mg}$ alloy after hot extrusion and the 4th passes of hydrostatic extrusion showing $\mathrm{BF}$ image taken on the LCS $(a)$ and SAED pattern $(b)$.

The results of mechanical properties are given in Figure 8 and Table III. In comparison to pure $\mathrm{Zn}$, the $\mathrm{Zn}-1 \mathrm{Mg}$ alloy was characterized by superior strength. It is clear that enhancement of YS and UTS was intensified by hydrostatic extrusion. In the case of pure $\mathrm{Zn}$, the hydrostatic extrusion process resulted in an increase in strength, but only to some extent. The stress-strain curves shown in Figure 8 indicate that pure $\mathrm{Zn}$ exhibits strain-hardening behavior. At each step of the plastic deformation process, the shape of strain-stress curves are nearly the same, with a wide region of necking, indicating good ductility from the beginning of the hydrostatic extrusion process. The addition of $\mathrm{Mg}$ provoked major changes in tensile behavior, the evolution of which may be observed with subsequent passes of the hydrostatic extrusion process. After the first pass, the $\mathrm{Zn}-1 \mathrm{Mg}$ alloy showed the widest range of uniform strain, indicating the highest strengthening effect. However, low ductility was noticed. Additional passes resulted in a further increase of YS and UTS, and finally reached 383 and $482 \mathrm{MPa}$, respectively. Hence, the $\mathrm{Zn}-1 \mathrm{Mg}$ alloy exhibits a rather narrow range of uniform strain and, which is also characteristic, the onset of non-uniform strain was preceded by a distinct UTS peak, which is followed by strain-softening. Considering changes in plasticity, a remarkable increase in the elongation to failure was noticed for the $\mathrm{Zn}-1 \mathrm{Mg}$ alloy fabricated by hydrostatic extrusion, where a constant increase in elongation with subsequent passes was achieved.

\section{DISCUSSION}

Pure $\mathrm{Zn}$ subjected to the hydrostatic extrusion process reveals a quite low susceptibility to grain refinement by multi-pass deformation, as evidenced by the orientation maps in Figure 2. Only the first pass reduces the grain size significantly. The presence of equiaxed grains on both of the cross-sections indicates that pure $\mathrm{Zn}$ fully recrystallized, due either to dynamic recrystallization during hydrostatic extrusion (adiabatic heating) or to static recrystallization after plastic deformation, reaching a stable state. However, the eventual static recrystallization process was considerably suppressed by water cooling of the extruded material at the end of a die. Therefore, no abnormal grain growth was observed. As a result, a microstructure with the predominance of grains free of defects and substantial share of HAGBs was achieved. This is also demonstrated by the coarsegrained texture that manifested on each pass of hydrostatic extrusion (Figure 6), and by the similar mechanical properties (Figure 8). Due to the low recrystallization temperature of pure $\mathrm{Zn}$ and recovery processes, it seems that further refinement of pure $\mathrm{Zn}$ is not possible during hydrostatic extrusion. Such a microstructure is also responsible for the mechanical 
LABG - LCS

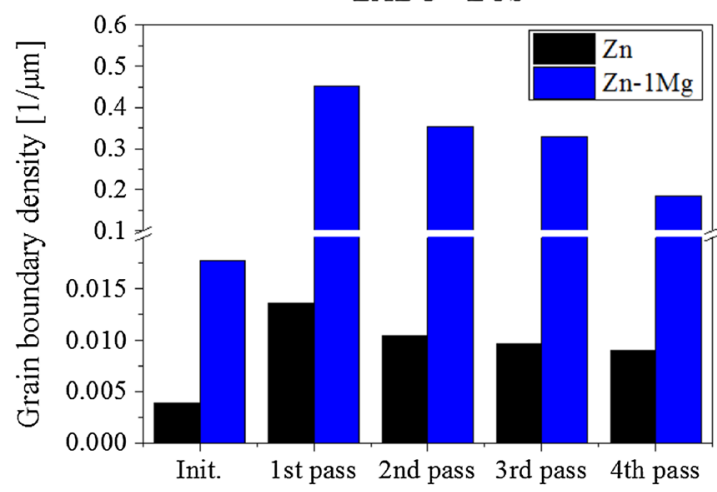

(a)

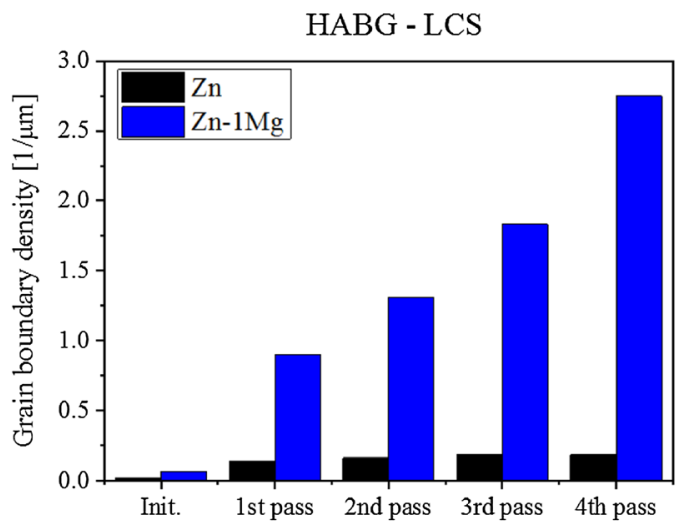

(c)

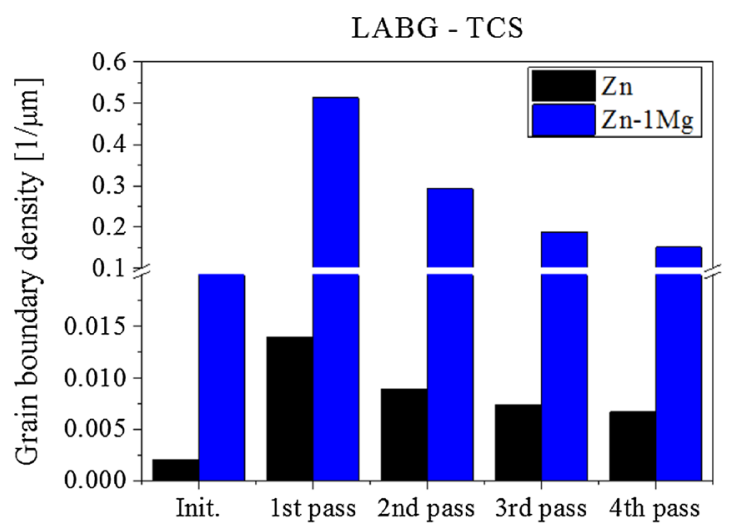

(b)

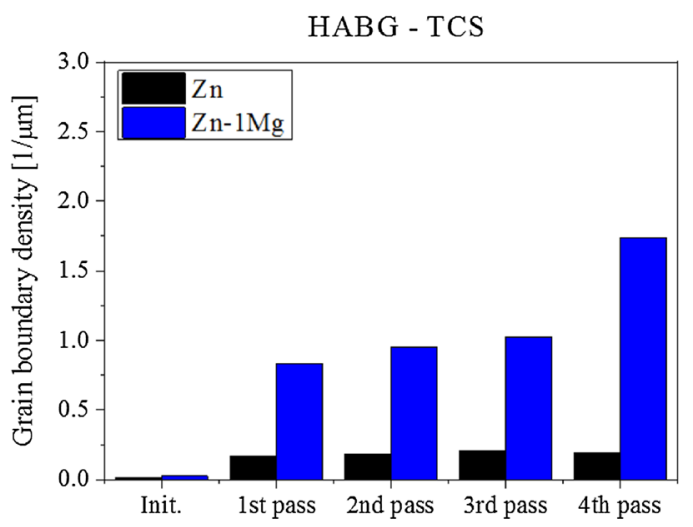

(d)

Fig. 5- Changes in the grain boundary density (vertical axis) of LAGB $(a)$, $(b)$ and HAGB $(c)$, $(d)$ after hot extrusion and after subsequent passes of hydrostatic extrusion, obtained from cross-sections of pure $\mathrm{Zn}$ and the $\mathrm{Zn}-1 \mathrm{Mg}$ alloy.

behavior of pure $\mathrm{Zn}$. Limited grain refinement provoked only a slight increase in strength compared to pure $\mathrm{Zn}$ after hot extrusion. However, the obtained stable microstructure with HAGBs contributes to a remarkable improvement of plasticity. This may be associated with the activation of the grain boundary sliding (GBS) process. $^{[31]}$ Such behavior is observed in materials deformed by SPD methods. ${ }^{[14,32,33]}$ Grain refinement and the accompanying increase in the volume of HAGB combined with a high deformation rate positively affects GBS.

To further reduce the grain size of $\mathrm{Zn}$ during hydrostatic extrusion, the addition of $\mathrm{Mg}$ is required. This prevents unwanted grain growth and allows a composite-like microstructure, in which the bands of hard eutectic mixture are arranged alternatingly with bands of softer fine grain $\alpha$ - $\mathrm{Zn}$ matrix to be obtained. The composite-like microstructure obtained in our experiment was possible due to hot extrusion of the as-cast material, which allows the arrangement of the eutectic almost in the form bands along the extrusion direction and facilitates further deformation by hydrostatic extrusion. A similar composite-like microstructure containing bands of $\alpha$ - $\mathrm{Zn}$ nanocrystallites and nanograins of $\mathrm{Mg}_{2} \mathrm{Zn}_{11}$ and $\mathrm{MgZn}_{2}$ intermetallic phases was observed for the $\mathrm{Zn}-\mathrm{Mg}$ hybrids subjected to HPT. ${ }^{[34,35]}$ Formation of the eutectic caused it to act as an effective barrier to dislocation movement and limits the recrystallization process, enabling the generation of a large number of LAGBs, which diminished gradually with subsequent passes of hydrostatic extrusion. This suggests that the microstructure of $\mathrm{Zn}-1 \mathrm{Mg}$ alloy obtained during the multi-pass hydrostatic extrusion process is a result of continuous dynamic recrystallization (cDRX), which is typically responsible for the grain refinement of the materials with a high stacking fault energy subjected to SPD techniques. ${ }^{[36]}$ Moreover, based on analysis of the $\mathrm{Zn}-1 \mathrm{Mg}$ alloy performed on LCS, a bimodal microstructure typical for other HCP metals ${ }^{[37,38]}$ was observed during the first stages of plastic deformation via hydrostatic extrusion. New grains grew at the boundaries of primary large grains. The bimodal microstructure that was formed appears to be a consequence of "hard orientation" (the basal plane is oriented perpendicular to the direction of an applied force ${ }^{[39]}$ ) in the initial state. Hard orientation appeared as a consequence of the activation of $\{10 \overline{1} 2\}$ compression twins, ${ }^{[40]}$ which exchange the $\langle 10 \overline{1} 0\rangle$ into $\langle 0002\rangle$ along the ED. ${ }^{[30]}$ As a result, a strong $\langle 0002\rangle$ fiber texture is formed after the first pass of hydrostatic extrusion. It seems that the formation of the $\langle 0002\rangle$ fiber texture is strongly correlated with the radial compression component of the hydrostatic extrusion process which squeezes the c-axis along the ED. It is important to note that, 

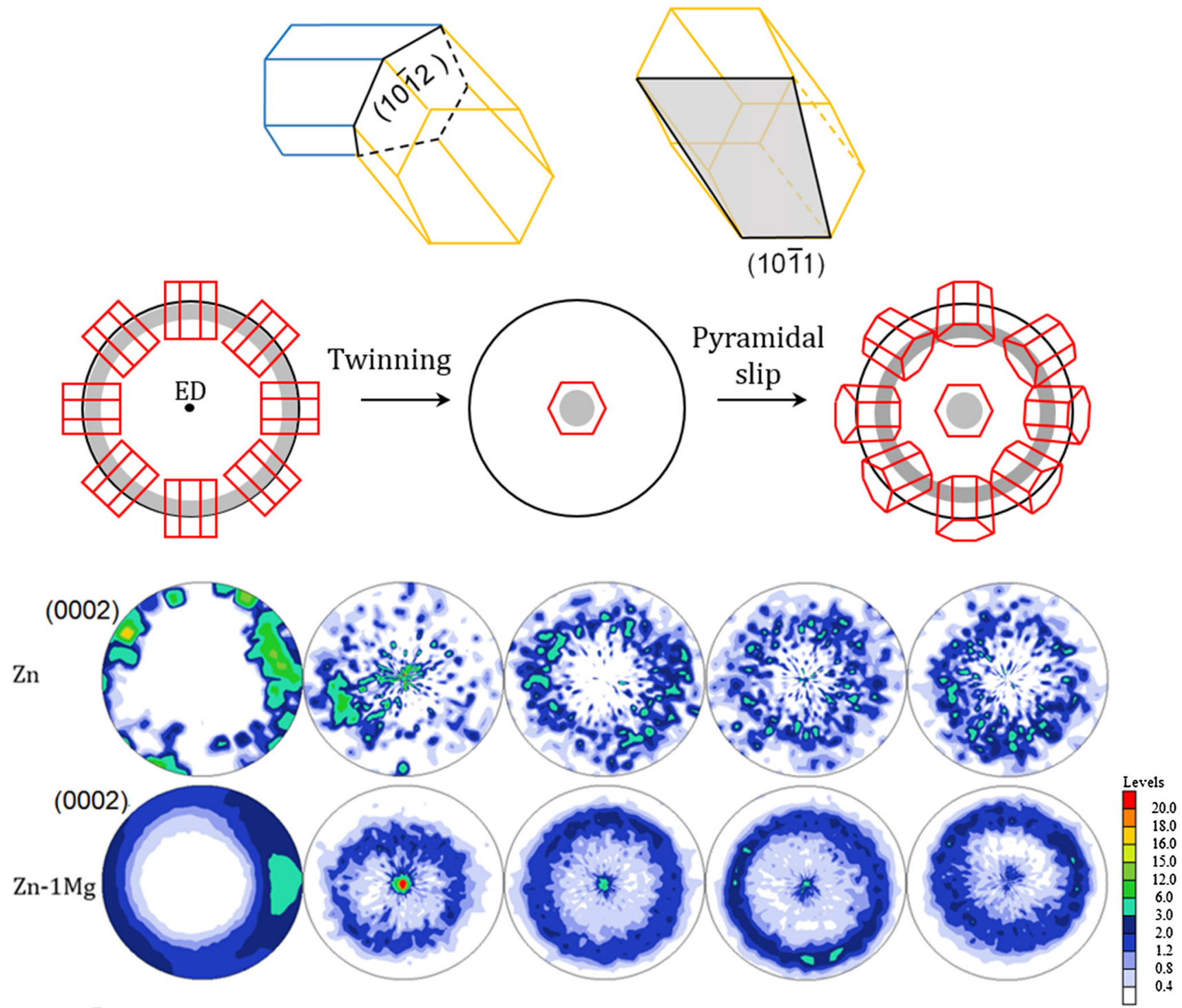

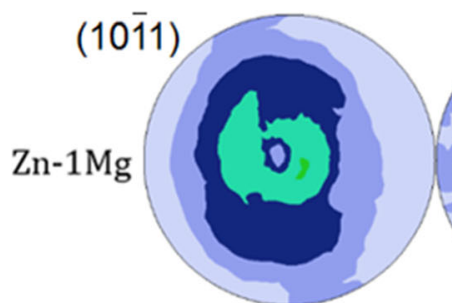

(a)

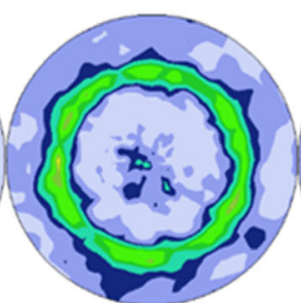

(b)

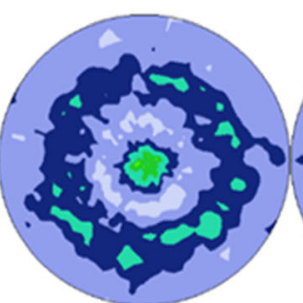

(c)

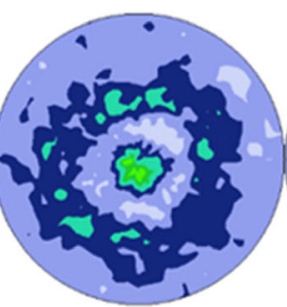

(d)

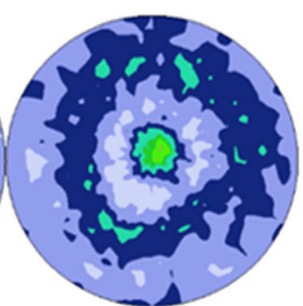

(e)

Fig. 6 - (0002) pole figures (PFs) of pure $\mathrm{Zn}$ (top row), $\mathrm{Zn}-1 \mathrm{Mg}$ (central row) and (1011) PFs of $\mathrm{Zn}-1 \mathrm{Mg}$ (bottom row): (a) after hot extrusion, calculated from synchrotron measurements, and after hydrostatic extrusion $(b)$ the first pass, $(c)$ the second pass, $(d)$ the third pass and $(e)$ the fourth pass calculated from EBSD measurements.

unlike most of the HCP metals, the c-axis of $\mathrm{Zn}$ is physically the longest lattice parameter. By "physically", we refer to the HCP structure constructed on the hexagonal base which does not correspond to the smallest rhombus (the crystallographic one). In this regard, the $\{10 \overline{1} 2\}$ twins in $\mathrm{Zn}$ are referred to as compression twins, not tension. For this reason, the c-axis is aligned along the ED after application of hydrostatic pressure. However, the capacity of $\{10 \overline{1} 2\}$ compression twins is limited, so subsequent passes activate secondary pyramidal slip systems to achieve deformation along the hexagonal c-axis. This changes the texture towards $\{10 \overline{1} 1\}$ fiber. The transition can be clearly seen in Figure 6. The effect of hydrostatic extrusion on texture components is also shown in Figure 7, in which the volume fraction of two fiber components after subsequent hydrostatic passes is presented. The growing amount of the $\langle 10 \overline{1} 1\rangle$ fiber 
component correlates quite well with the total elongation, which also increases as the number of passes increases. The proposed explanation was supported by simulation using a self-consistent model. The given texture evolution was justified by increasing activation of pyramidal slip systems (Figure 9). These calculations clearly show that combining hydrostatic extrusion and $\mathrm{Mg}$ alloying enables activation of the pyramidal slip system in the $\mathrm{Zn}-1 \mathrm{Mg}$ alloy, which leads to a strong $\langle 10 \overline{1} 1\rangle$ fiber component. Replacement of the hard $\langle 0002\rangle$ orientation by the $\langle 10 \overline{1} 1\rangle$ component is suitable for plastic deformation, since it makes the material less prone to strain localization and to brittle failure.

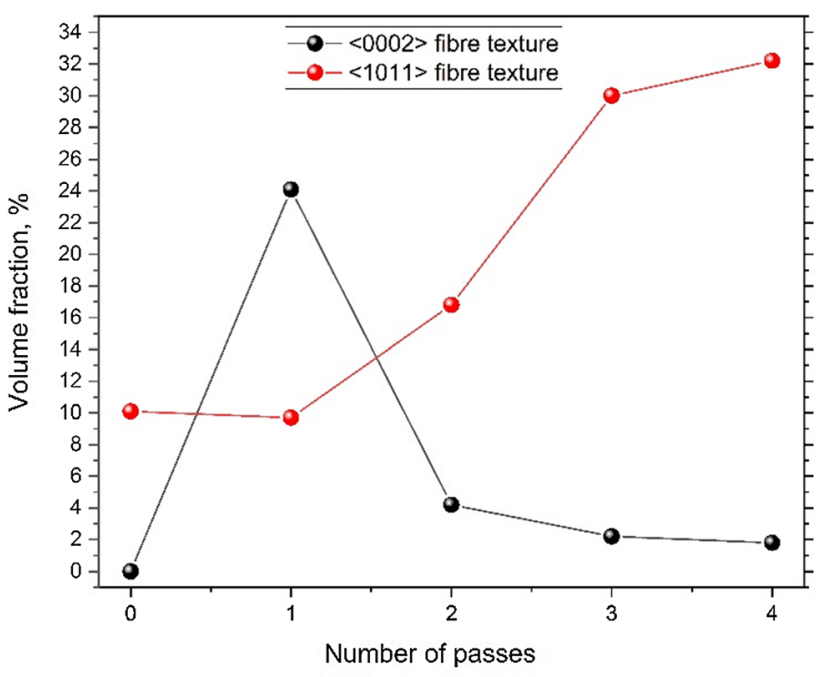

Fig. 7-Volume fraction of two fiber components after subsequent hydrostatic passes. The calculated values are given with a spread of \pm 15 deg.

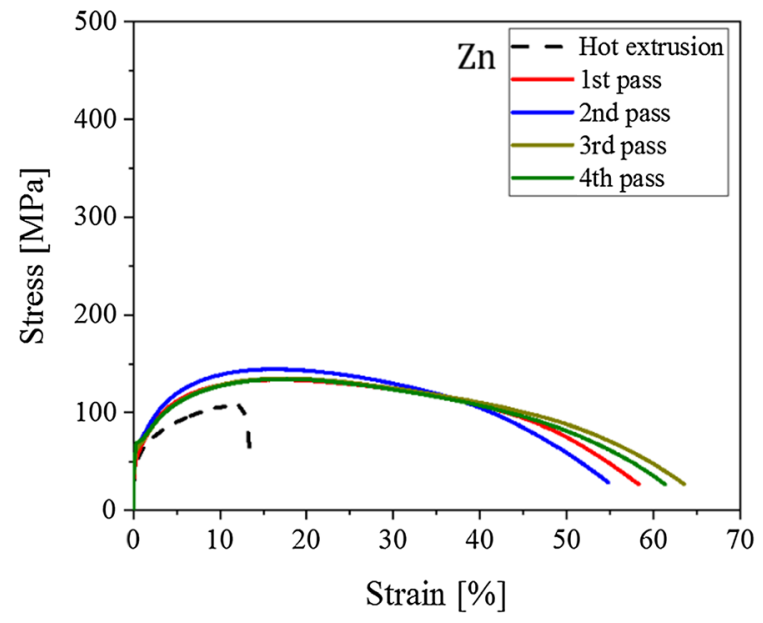

(a)
Overall, these results show that the application of multi-pass hydrostatic extrusion instead of one operation is more beneficial for better grain refinement, greater elongation and suppression of the recrystallization processes. ${ }^{[21]}$

The mechanical properties of the $\mathrm{Zn}-1 \mathrm{Mg}$ alloy subjected to multi-pass hydrostatic extrusion are a direct result of the microstructure and texture formed during plastic deformation. Significant grain refinement caused the $\mathrm{Zn}-1 \mathrm{Mg}$ alloy to have the highest strength among all of the investigated materials. The gradual decrease in grain size with subsequent passes revealed that mechanical properties are strictly dependent on them, which could be observed on strain-stress curves. At the beginning of plastic deformation of the $\mathrm{Zn}-1 \mathrm{Mg}$ alloy, the curves showed a sharp increase to the critical value of stress, with increasing strain due to a large number of dislocations present in the material. However, after first pass, because of an insufficient number of slip systems (hard orientation with $\langle 0002\rangle$ fiber texture), the material fractured without any necking. Subsequently, modified microstructure and texture evolution caused by further passes of hydrostatic extrusion affected the deformation behavior of the material. The stress-strain curves yield a peak, and then the flow stress decreased with a negative work hardening rate followed by unstable deformation. This may be due to the fact that, in the ultrafine-grained materials, the sources of generation of dislocation are the grain boundaries rather than their interiors. ${ }^{[1]}$ Moreover, the grain boundaries not only generate dislocation, but also can annihilate or absorb them, and grain boundary character determines which processes will dominate. ${ }^{[42]}$ Thus, it is likely that the observed yield peak appeared as a consequence of insufficient dislocation mobility related to an increased volume fraction of the grain boundaries, which increased the probability of their interactions with dislocations. This results in high stored energy of grain boundaries, and favors the initiation of dynamic recovery and recrystallization processes. ${ }^{[43,44]}$ Further necking

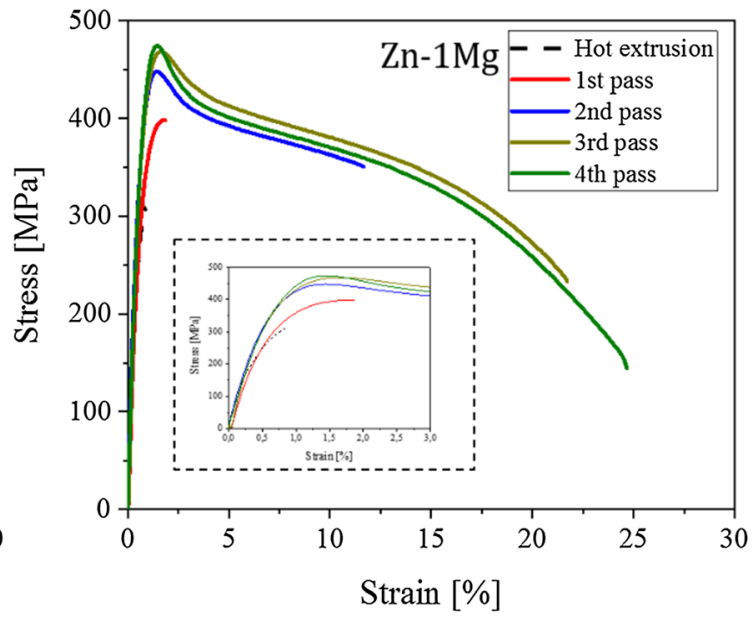

(b)

Fig. 8- Strain-stress curves obtained for materials after hot extrusion and hydrostatic extrusion on each pass for $(a)$ pure $\mathrm{Zn}$ and $(b) \mathrm{Zn}-1 \mathrm{Mg}$ alloy. 
Table III. The Mechanical Properties Obtained for All Investigated Materials

\begin{tabular}{lcccr}
\hline Sample & Hot Extrusion & 1st Pass & 2nd Pass & 3rd Pass \\
\hline Zn & & & & \\
YS [MPa] & $47 \pm 4$ & $55 \pm 0.2$ & $63 \pm 1$ & $63 \pm 0.3$ \\
UTS [MPa] & $103 \pm 4$ & $134 \pm 1$ & $143 \pm 1$ & $136 \pm 1$ \\
$E[$ Pct] & $10 \pm 4$ & $54.6 \pm 4$ & $54.3 \pm 1$ & $62.4 \pm 1$ \\
Zn-1Mg & $222 \pm 6$ & $296 \pm 9$ & $351 \pm 21$ & $375 \pm 37$ \\
YS [MPa] & $311 \pm 1$ & $397 \pm 3$ & $449 \pm 2$ & $471 \pm 4$ \\
UTS [MPa] & $0.9 \pm 1$ & $1.7 \pm 0.2$ & $8 \pm 3$ & $18 \pm 6$ \\
$E[$ Pct] & & & & $383 \pm 39$ \\
\hline
\end{tabular}

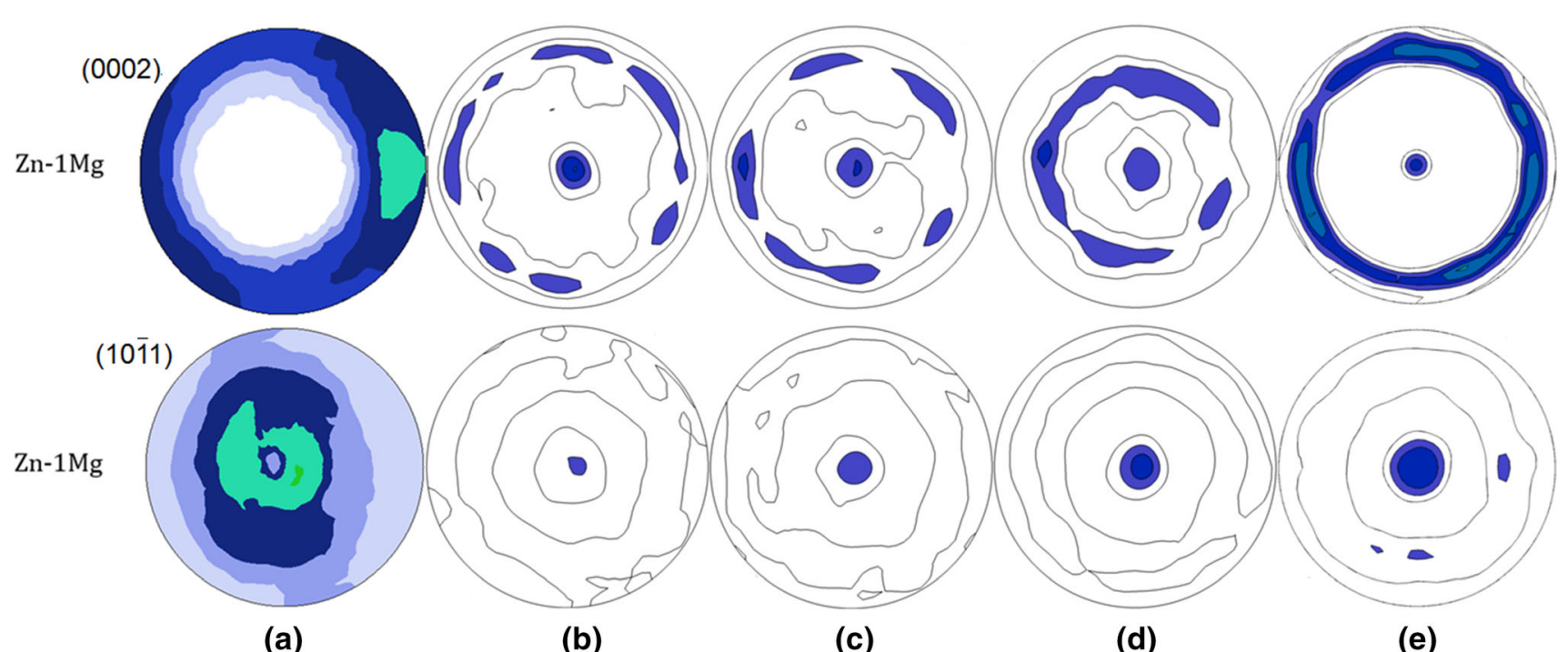

Fig. 9-Initial experimental $(a)$ and simulated (0002) and (1011) PFs after hydrostatic extrusion $(b)$ the first pass, $(c)$ the second pass, $(d)$ the third pass and $(e)$ the fourth pass.

and softening of the material, observed from the second pass, may be the consequence of dynamic recrystallization, and this inhomogeneous strain intensifies for subsequent passes of hydrostatic extrusion. Such microstructural-dependent mechanical behavior was observed in various metals, such as commercial purity aluminum, interstitial free steel and vanadium subjected to different SPD processes (ECAP, ARB - accumulative roll bonding, HPT). ${ }^{[41,42,44,45]}$ In these studies, different grain sizes were obtained as a result of annealing after the SPD process, where the grain size was controlled by cDRX induced during multi-pass hydrostatic extrusion. The dependence between the microstructure and the mechanical properties obtained for the investigated materials is shown in Figure 10.

\section{CONCLUSIONS}

The effect of multi-pass hydrostatic extrusion preceded by hot extrusion and the addition of $\mathrm{Mg}$ on the microstructure evolution of $\mathrm{Zn}$ was examined in this work. It has already been reported in our previous works, ${ }^{[20,21]}$ and is demonstrated well in the present one, that the hydrostatic extrusion process contributes to great grain refinement of low-alloyed zinc, which is responsible for an improvement of mechanical properties. However, more homogeneous microstructure providing uniform mechanical properties throughout the entire extruded material was obtained when the hydrostatic extrusion process was preceded by hot extrusion as compared to the $\mathrm{Zn}-1 \mathrm{Mg}$ alloy in as-cast state. ${ }^{[21]}$ Achievement of significant grain refinement of $\mathrm{Zn}$, which results in the increase in its strength and plasticity, may be possible only by the combination of Mg addition and hydrostatic extrusion. Using either of these operations individually does not improve the mechanical properties sufficiently to fulfil requirements for biodegradable stents. Furthermore, due to comprehensive analysis of the microstructure evolution and comparison with pure $\mathrm{Zn}$, it was possible to observe changes and to understand the mechanisms behind them. The results may be summarized as follows:

1. Applying hot extrusion prior to multi-pass hydrostatic extrusion allowed the formation of an initial 

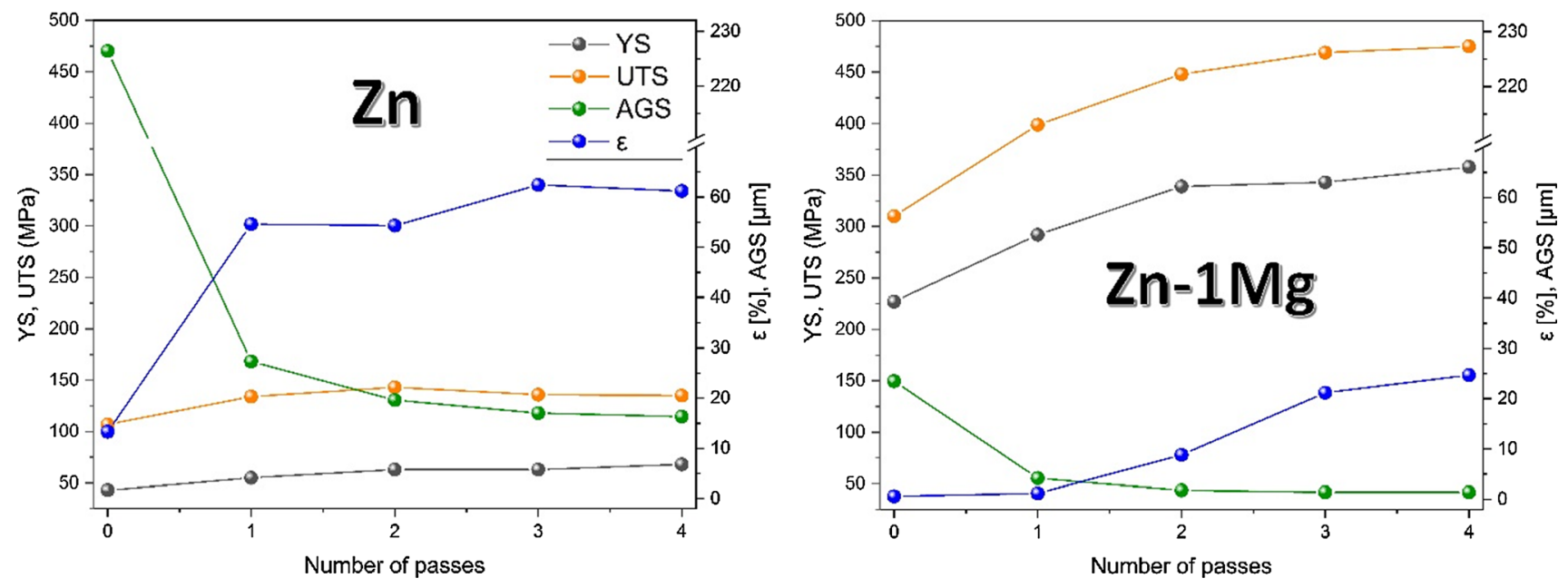

Fig. 10 - Changes in mechanical properties and average grain size for materials after hot extrusion and on each pass of hydrostatic extrusion for pure $\mathrm{Zn}$ and $\mathrm{Zn}-1 \mathrm{Mg}$ alloy.

microstructure with near bands of fragmented eutectic, elongated in ED, which facilitates deformation by means of hydrostatic extrusion.

2. The microstructure observation performed after each pass of hydrostatic extrusion indicates that grain refinement occurred mainly by continuous dynamic recrystallization, limited in the case of the $\mathrm{Zn}-1 \mathrm{Mg}$ alloy.

3. Hydrostatic extrusion changes the initial $\langle 10 \overline{1} 1\rangle$ fiber texture to a $\langle 0002\rangle$ and $\langle 10 \overline{1} 1\rangle$ double fiber texture in which the $\langle 0002\rangle$ component decreases with each pass of hydrostatic extrusion.

4. With an increasing number of hydrostatic passes, the $\langle 10 \overline{1} 1\rangle$ texture component also increases, which results in improved formability.

\section{ACKNOWLEDGMENTS}

This work was financially supported by the National Science Center (Poland) in the frame of the project UMO-2016/23/B/ST8/00724.

\section{OPEN ACCESS}

This article is licensed under a Creative Commons Attribution 4.0 International License, which permits use, sharing, adaptation, distribution and reproduction in any medium or format, as long as you give appropriate credit to the original author(s) and the source, provide a link to the Creative Commons licence, and indicate if changes were made. The images or other third party material in this article are included in the article's Creative Commons licence, unless indicated otherwise in a credit line to the material. If material is not included in the article's Creative Commons licence and your intended use is not permitted by statutory regulation or exceeds the permitted use, you will need to obtain permission directly from the copyright holder. To view a copy of this licence, visit http://creat ivecommons.org/licenses/by/4.0/.

\section{REFERENCES}

1. Y. Zheng, X. Gu, and F. Witte: Mater. Sci. Eng. R, 2014, vol. 77, p. 1 .

2. H. Hermawan, D. Dube, and D. Mantovani: Acta Biomater., 2010, vol. 6, p. 1693

3. E. Mostaed, M. Sikora-Jasinska, J.W. Drelich, and M. Vedani: Acta Biomater., 2018, vol. 71, pp. 1-23.

4. P.K. Bowen, J. Drelich, and J. Goldman: Adv. Mater., 2013, vol. 25 , p. 2577.

5. J. Venezuela and M.S. Dargusch: Acta Biomater., 2019, vol. 87, pp. $1-40$.

6. D. Hernández-Escobar, S. Champagne, H. Yilmazer, B. Dikici, C.J. Boehlert, and H. Hermawan: Acta Biomater., 2019, vol. 97, pp. 1-22.

7. G.K. Levy, J. Goldman, and E. Aghion: Metals, 2017, vol. 7, p. 402 .

8. G.K. Levy, A. Leon, A. Kafri, Y. Ventura, J.W. Drelich, J. Goldman, R. Vago, and E. Aghion: J. Mater. Sci. Mater. Med., 2017, vol. 28(11), p. 174.

9. H. Jin, S. Zhao, R. Guillory, P.K. Bowen, Z. Yin, A. Griebel, J. Schaffer, E.J. Earley, J. Goldman, and J.W. Drelich: Mater. Sci. Eng. C, 2018, vol. 84, pp. 67-79.

10. D. Vojtech, J. Kubasek, J. Serak, and P. Novak: Acta Biomater., 2011, vol. 7, pp. 3515-22.

11. J. Kubasek, D. Vojtech, I. Pospísilova, A. Michalcova, and J. Maixner: Int. J. Miner. Metall. Mater., 2016, vol. 23, pp. $1167-75$

12. E. Mostaed, M. Sikora-Jasinska, A. Mostaed, S. Loffredo, A.G. Demir, B. Previtalia, D. Mantovani, R. Beanland, and M. Vedani: J. Mech. Behav. Biomed. Mater., 2016, vol. 60, pp. 581-602.

13. M. Wạtroba, W. Bednarczyk, J. Kawałko, K. Mech, M. Marciszko, G. Boelter, M. Banzhaf, and P. Bała: Mater. Des., 2019, vol. 183, p. 108154.

14. W. Bednarczyk, M. Wạtroba, J. Kawałko, and P. Bała: Mater. Sci. Eng. A, 2019, vol. 748, pp. 357-66.

15. K. Pieła, M. Wróbel, K. Sztwiertnia, M. Jaskowski, J. Kawałko, M. Bieda, M. Kiper, and A. Jarzębska: Mater. Des., 2017, vol. 117, pp. 111-20.

16. D. Hernandez-Escobar, Z. Ur Rahman, H. Yilmazer, M. Kawasaki, and C.J. Boehlert: Philos. Mag., 2019, vol. 99, pp. $557-84$. 
17. M. Wạtroba, W. Bednarczyk, J. Kawałko, S. Lech, K. Wieczerzak, T.G. Langdon, and P. Bała: Metall. Mater. Trans. A, 2020, vol. 51A, pp. 3335-48.

18. W. Pachla, A. Mazur, J. Skiba, M. Kulczyk, and S. Przybysz: Int. J. Mater. Res., 2012, vol. 103, pp. 580-89.

19. W. Pachla, M. Kulczyk, M. Sus-Ryszkowska, A. Mazur, and K.J. Kurzydlowski: J. Mater. Process. Technol., 2008, vol. 205, pp. 173-82.

20. A. Jarzębska, M. Bieda, J. Kawałko, Ł. Rogal, P. Koprowski, K. Sztwiertnia, W. Pachla, and M. Kulczyk: Mater. Lett., 2018, vol. 211, pp. 58-61.

21. A. Jarzębska, M. Bieda, J. Kawałko, P. Koprowski, Ł. Rogal, R. Chulist, B. Kania, K. Sztwiertnia, W. Pachla, and M. Kulczyk: IOP Conf. Ser., 2018, vol. 375, p. 012008.

22. A. Jarzębska, W. Pachla, M. Bieda, and K. Sztwiertnia, Patent application no. P.429952.

23. D. Wojtas, K. Wierzbanowski, R. Chulist, W. Pachla, M. Bieda-Niemiec, A. Jarzębska, Ł. Maj, J. Kawałko, M. Marciszko-Wiąckowska, M. Wroński, and K. Sztwiertnia: J. Alloys Compd., 2020, vol. 837, p. 155576.

24. R. Chulist, L. Straka, H. Seiner, A. Sozinov, N. Schell, and T. Tokarski: Mater. Des., 2019, vol. 171, p. 107703.

25. www.crystorient.com.

26. H.R. Piehler and A.S.M. Handbook: Fundamentals of Modeling for Metals Processing, ASM International, Cleveland, 2009, vol. 22A.

27. P.V. Houtte, S. Li, M. Seefeldt, and L. Delannay: Int. J. Plast., 2005, vol. 21, pp. 589-624.

28. V. Paidar, J. Capek, and A. Ostapovets: Philos. Mag. Lett., 2019, vol. 10 , pp. 437-45.

29. Y.N. Wang and J.C. Huang: Mater. Chem. Phys., 2003, vol. 81, pp. 11-26.

30. M.G. Jiang, C. Xu, H. Yan, G.H. Fan, T. Nakata, C.S. Lao, R.S. Chen, S. Kamado, E.H. Han, and B.H. Lu: Acta Mater., 2018, vol. 157, pp. 53-71.
31. J. Gubicza: Defect Structure in Nanomaterials, 1st ed., Woodhead Publishing, Philadelphia, 2012.

32. W. Bednarczyk, J. Kawałko, M. Wạtroba, and P. Bała: Mater. Sci. Eng. A, 2018, vol. 723, pp. 126-33.

33. W. Bednarczyk, M. Wạtroba, J. Kawałko, and P. Bała: Mater. Sci. Eng. A, 2019, vol. 759, pp. 55-58.

34. D. Hernández-Escobar, J. Marcus, J.K. Han, R.R. Unocic, M. Kawasaki, and C.J. Boehlert: Mater. Sci. Eng. A, 2020, vol. 771 , p. 138578.

35. D. Hernández-Escobar, R.R. Unocic, M. Kawasaki, and C.J. Boehlert: J. Alloys Compd., 2020, vol. 831, p. 154891.

36. K. Huang and R.E. Loge: Mater. Des., 2016, vol. 111, pp. 548-54.

37. J. Kawałko, M. Wroński, M. Bieda, K. Sztwiertnia, K. Wierzbanowski, D. Wojtas, M. Lagoda, P. Ostachowski, W. Pachla, and M. Kulczyk: Mater. Charact., 2018, vol. 141, pp. 19-31.

38. N. Bozzolo, N. Dewobroto, H.R. Wenk, and F. Wagner: J. Mater. Sci., 2007, vol. 42, pp. 2405-16.

39. D.E. Solas, C.N. Tome, O. Engler, and H.R. Wenk: Acta Mater., 2001, vol. 49, p. 3791.

40. T.B. Britton, F.P.E. Dunne, and A.J. Wilkinson: Proc. R. Soc. A, 2015, vol. 471, p. 20140881.

41. N. Tsuji, Y. Ito, Y. Saito, and Y. Minamino: Scr. Mater., 2002, vol. 47, pp. 893-99.

42. P.L. Sun, C.Y. Yu, P.W. Kao, and C.P. Chang: Scr. Mater., 2005, vol. 52, pp. 265-69.

43. Q. Guo-Zheng: Characterization for Dynamic Recrystallization Kinetics Based on Stress-Strain Curves, Chapter 2, InTech, Rijeka, 2013.

44. C.Y. Yu, P.W. Kao, and C.P. Chang: Acta Mater., 2005, vol. 53, pp. 4019-28.

45. Y. Huang, M. Lemang, N.X. Zhang, P.H.R. Pereira, and T.G. Langdon: Mater. Sci. Eng. A, 2016, vol. 655, pp. 60-69.

Publisher's Note Springer Nature remains neutral with regard to jurisdictional claims in published maps and institutional affiliations. 